\title{
The Degree of Abstraction in Solving Addition and Subtraction Problems
}

\author{
Vicente Bermejo ${ }^{1}$ and Juan José Díaz ${ }^{2}$ \\ ${ }^{1}$ Universidad Complutense de Madrid \\ ${ }^{2}$ Universidad Autónoma de Zacatecas (Mexico)
}

\begin{abstract}
In this study, the incidence of the degree of abstraction in solving addition and subtraction problems with the unknown in the first term and in the result is analyzed. Ninety-six students from first grade to fourth grade in Primary Education (24 students per grade) solved arithmetic problems with objects, drawings, algorithms, and verbal problems. The participants were interviewed individually and all sessions were video-taped. The results indicate a different developmental pattern in achievement for each school grade depending on the levels of abstraction. The influence of the level of abstraction was significant, especially in first graders, and even more so in second graders, that is, at the developmental stage in which they start to learn these arithmetic tasks. Direct modeling strategies are observed more frequently at the concrete and pictorial level, counting strategies occur at all levels of abstraction, whereas numerical fact strategies are found at higher levels of abstraction.
\end{abstract}

Keywords: abstraction level, arithmetic problems, strategies, mathematical development

\begin{abstract}
En este estudio se analiza la incidencia del grado de abstracción en la resolución de problemas de suma y resta con la incógnita en el primer término y en el resultado. Noventa y seis alumnos de primero a cuarto curso de Educación Primaria (24 escolares por curso) resuelven tareas aritméticas con objetos, dibujos, algoritmos y verbales. Los participantes se entrevistaron de manera individual y se registraron en vídeo todas las sesiones. Los resultados indican un patrón evolutivo diferente en el rendimiento para cada curso escolar según los niveles de abstracción. Resulta significativa la influencia del nivel de abstracción sobre todo en primero y más aún en segundo curso, es decir, en el momento evolutivo en que se inicia el aprendizaje de estas tareas aritméticas. Las estrategias modelado directo se manifiestan más en el nivel concreto y pictórico, las estrategias conteo ocurren en todos los niveles de abstracción, mientras que las estrategias hechos numéricos se encuentran en los niveles de mayor abstracción.

Palabras clave: nivel de abstracción, problemas aritméticos, estrategias, desarrollo matemático
\end{abstract}

Correspondence concerning this article should be addressed to Vicente Bermejo, Facultad de Psicología, Campus de Somosaguas, Universidad Complutense, 28223 Madrid, Spain. E-mail: bermejo@psi.ucm.es

Translation: Virginia Navascués Howard. 
The PISA report (Organisation for Economic Cooperation and Development/PISA, 2005) has once more revealed the low mathematical achievement of Spanish and Mexican students, making it necessary to increase the effort in the educational setting in general and in mathematical research in particular. From this perspective, this study represents an attempt to analyze the importance of the degree of abstraction when solving problems of adding and subtracting in the first four years of Primary Education.

According to the constructivist theoretical framework, children learn to solve arithmetic problems by elaborating cognitive strategies in an active and informal way, at early developmental stages. The degree of abstraction of the task may or may not be an important facilitating factor to solve arithmetic problems. We assume that children first learn at a concrete level, so as to subsequently develop their mathematical efficacy at more abstract and complex levels. Although there are many investigations on arithmetic problems in general, and, more specifically, on the semantic structure, the degree of difficulty, the developmental level, the strategies used, and the mistakes made by students (see, for example, Bermejo, 1990, 2004), there is a remarkable shortage of studies that directly address the degree of abstraction of such problems and its incidence in student's mathematical achievement.

Verbal problems of adding and subtracting are usually classified according to their semantic structure into four types: Change, Combination, Comparison, and Equaling (see the diverse classifications in: Bermejo, 1990; Bermejo, Lago, \& Rodríguez, 1998; Bermejo, Lago, Rodríguez, Dopico, \& Lozano, 2002; Carpenter \& Moser, 1982, 1983; Carpenter, Ansell, Franke, Fennema, \& Weisbeck, 1993; Riley \& Greeno, 1988; Riley, Greeno, \& Heller, 1983; Vergnaud, 1982). In this research, we shall only use problems of change, which, along with problems of combination, are the easiest for children (Bermejo et al., 2002). Problems of change are characterized by the presence of an implicit or explicit action that modifies an initial quantity either by increasing (addition) or decreasing (subtraction). An example of an additive problem is: "Luis has 8 biscuits. Silvia gives him 4 more. How many biscuits does Luis have now?" whereas an example of subtraction is: "Luis has 8 biscuits He gives 4 biscuits to Silvia. How many biscuits does Luis have now?" On the one hand, the location of the unknown in the first, second, or third term of the problem changes the difficulty to solve it, as well as the kind of solution strategies employed. Thus, if the unknown is placed in the first term, the difficulty is maximum, whereas the lowest degree of difficulty occurs if it is placed in the result (Bermejo et al., 2002; Carpenter, 1986; Grouws, 1992; Hiebert, 1982). An example of a problem of additive change with the unknown in the first term is: "María has some chocolates. Juan gives her 3 chocolates. Now María has 7 chocolates. How many chocolates did María have at the beginning?" And an example of a subtraction problem with the unknown in the second term is: "Maria has 7 chocolates. She gives some chocolates to Juan. Now María has 4 chocolates. How many chocolates did she give to Juan?"

Regarding the development of comprehension of verbal problems in general, Bergeron and Hersovics (1990) found four developmental levels in solving verbal problems, which have been confirmed by other authors (Chen, 1999; Christou \& Philippou, 1998). At the first level, children from 5 to 6 years of age know how to count a quantity of elements in a series. With this knowledge, addition problems of change with the unknown in the result are solved. At the second level, children from 6 to 7 years old causally relate the change produced in the initial series and the action that caused this change. At this stage, in problems of change, they are capable of estimating the direction of the change (increase or decrease) and of relating it to the operations of addition and subtraction, so that, for example, they solve problems of change with the unknown in the second addend by counting from the lowest quantity to the highest. At the third level, children between 7 and 8 years of age have acquired the part-part-all schema that enables them to cope with a static situation in which they must impose a structure on the situation described in the verbal problem. At this level, they solve problems of change with the unknown in the first term. Finally, at the fourth level, which does not affect problems of change, children of 9 to 10 years of age have the necessary schemas to solve the more complex comparison problems.

Children of the first grade of primary education display a high level of success in addition and subtraction problems with the unknown in the result. However, this level decreases when the unknown is located in the second term, and even more so when in the first term (Bebout, 1990; Bermejo, 1990; Carpenter, Hiebert, \& Moser, 1981, 1983; De Corte \& Verschaffel, 1987).

From the constructivist framework, abstraction is understood as a process that goes from the concrete towards the abstract by developmental levels (Kamii, Kirkland, \& Lewis, 2001). Piaget (1951), for example, distinguished two kinds of abstraction: empirical and reflective. Empirical abstraction focuses on certain properties of the object and ignores others. These properties are perceived through the senses and only those that the person wants to abstract are selected. Reflective abstraction involves the mental relation between objects, such as "different," "similar," "two" (logicalmathematical knowledge), etc. The properties of the objects are abstracted from the objects, whereas the relations are abstracted from mental actions (thinking) performed with the objects. When making the theoretical distinction between empirical and reflective abstraction, Piaget proposed that, in the child's psychological reality, one cannot take place without the other. For example, the relation "different" cannot be established if all the objects are identical. Nor can knowledge of "red" be established unless one possesses the category of "color" and the category of "red." Reflective abstraction 
cannot take place independently of empirical abstraction before the age of 6 years. But once children construct the number, they are capable of placing these relations within relations without empirical abstraction. For example, to place four "twos" within relations, children deduce that $2+2+2$ $+2=(2+2)+(2+2)$, that $4 \times 2=8$. Moreover, if $4 x=$ 8 , then $x$ will be equal to 2 , without the intervention of empirical abstraction.

Kato, Kamii, Ozaki, and Nagahiro (2002) found that the relation between levels of abstraction and representation indicates that children can represent at the same level of abstraction or at a lower level, but not above this level. In other words, students generally represent series of objects at their respective levels of abstraction.

In this investigation, the following levels of abstraction were taken into account: concrete, drawings, numerical, and verbal. These levels follow a progressive order of comprehension in the child (Canobi, Reeve, \& Pattison, 2003; Fuson, Smith, \& LoCicero, 1997). This was confirmed by Maccini and Hughes (2000) with a teaching sequence of three levels: concrete (manipulation of physical objects), semi-concrete (representation with drawings), and abstract (use of mathematical symbols).

With regard to the concrete level, many authors have used blocks successfully in many mathematical investigations (Fuson \& Briars, 1990; Fuson \& Burghardt, 2003; Hughes (1986); Labinowicz, 1985; Resnick \& Omanson, 1987; Wearne \& Hiebert, 1988). For example, Hughes investigated in 5- to 7-year-old children the use of blocks to solve problems $(1+7=8)$, finding that this facilitated comprehension of the algorithm. Along these lines, Kennedy and Tipps (1994) suggested that concrete materials promote easier comprehension of difficult mathematical concepts. Manipulation of objects ensures that the students connect their abstract mathematical concepts to real objects. More recently, Zhou and Zhang (2003) found that 8-year-olds solve verbal addition problems with objects more easily than subtraction problems.

In contrast, other authors dispute the usefulness of manipulations of concrete materials in relation to the acquisition of logical-mathematical knowledge (Kamii, Lewis, \& Kirkland, 2001a). Concrete manipulations are preferred to start thinking about the solution of a problem, but logical-mathematical knowledge consists of constructing relations by means of reflective abstraction; mathematical relations do not exist in objects but in the mind, and they are not acquired by empirical abstraction but rather by reflective abstraction.

Concerning the use of drawings to solve problems, Bruner (1966) suggested that the pictorial level would act as a connection between the concrete and abstract levels, because some characteristics of the problem can be inferred more easily from drawings, as they are more explicit. This idea has been verified in investigations of the use of pictorial representations to better understand verbal problems, such as studies that show that child comprehension is better when problems are presented with drawings than when only presented verbally. Cohen and Stover (1981) and Yancey (1981) declare that students who solve verbal problems by means of drawings do better than students who do not elaborate them. Likewise, Quintero (1983) found evidence of this when asking children from fifth, sixth, and seventh grade about their selection of a drawing that best represented the situation described in the problem. Students learned so solve the problems better when they used schematic drawings adapted to the semantic structure of the problem (De Corte \& Verschaffel, 1985; Lindvall, Tamburino \& Robinson, 1982; Willis \& Fuson, 1988; Wolters, 1983). Moyer, Sowder, Threadgill-Sowder, and Moyer (1984) found that the achievement of children from third grade until seventh grade was better for problems presented with drawings than for verbal problems. Along these lines, Larkin and Simon (1987) reported that children gather more efficient information from a drawing than from the text when they solve the problem.

Fuson and Willis (1989) analyzed the use of drawings by students of second grade when solving three-digit verbal addition and subtraction problems. The children showed competence to identify the semantic structure of the problem, write the numbers of the problem in the appropriate places in the drawing, and determine whether to add or subtract the two known numbers. Most of the high-achievement children chose the appropriate strategy for almost all the problems, and two thirds of the average-achievement children did so in $60 \%$ of the problems.

Considering the numerical level, the question about the starting point to teach addition and subtraction is frequently posed: Should learning addition and subtraction start with the algorithm (numbers and symbolic operation) or with concrete representations? This question is not a confrontation of the concrete versus the abstract, but an epistemological question. Cai (2000) examined 232 American children and 310 Chinese children from sixth grade in solving mathematical tasks with algorithm and concrete and visual material. The results indicated that the Chinese participants preferred to use algorithms and symbolic representations, whereas the American students chose concrete, visual representations. Likewise, Selva and Brandao (2000) investigated children from 4 to 6 years of age about how they used written numbers to solve verbal problems, finding, among other things, that the numbers help perform the calculus and represent the verbal problems to oneself. In contrast, Kamii, Lewis, and Kirkland (2001b) examined why children find subtraction more difficult than addition. First, they asked 33 preschool children about transferring blocks from a glass to a bottle. In the second experiment, they asked 21 first graders and 38 fourth graders about addition algorithms $(8+2)$ and their corresponding subtractive form $(10-8)$. They concluded that subtraction is more difficult than addition because children deduce the differences from their previous knowledge of the addition. 
In another study, Kamii et al. (2001) interviewed 201 first graders about addition, finding that all these students were familiar with the algorithm, but only about $40 \%$ wrote the traditional algorithm correctly. An important point concerns the use of the equal sign (=). In $3+2=5$, many children write the 3 and the 2 without the plus sign (+). Some children write the plus sign without writing the equal sign, but none of them write the equal sign without writing the plus sign. Therefore, the equal sign appears later than the plus sign, probably because the relations among 3, 2, and 5 involve a hierarchical and reversible relation that is difficult for small children to understand. When adding two numbers, two parts are combined to build a whole. In contrast, the plus (+) relations between the two original parts $(3+2)$ taken alone, do not involve a hierarchical relation.

In children between 6 and 7 years, thinking is flexible and reversible. Reversibility refers to the skill to mentally perform two opposite actions simultaneously (separate the whole into two parts and reunite the parts within the whole). In a physical material action, it is impossible to do simultaneously two opposite things. But this is possible in the mind when thinking (reflective abstraction) is flexible and reversible. The child understands the total series when the parts can be reunited only in the mind. Thus, the use of the equal sign is not very frequent and the relation among the three numbers $(3,2$, and 5$)$ is considered an expression of $1^{\text {st }}$-grade children's difficulty to elaborate hierarchical part-whole relations. Therefore, children cannot represent (externalize) a part-whole relation that does not exist in their minds.

The verbal level represents the highest degree of abstraction in solving addition and subtraction problems. The difference with regard to the previous level of abstraction lies in the fact that this level implies mastering semantic relations or the meaning of the quantities of the problem, beyond the arbitrary symbolic relations established in the algorithm.

The educational importance of the levels of abstraction has been acknowledged in various educational instances such as the Association of Mathematical Instruction of Japan (Ginbayashi, 1984; Hatano, 1980, 1982) and the National Council of Teachers of Mathematics of the United States (NCTM, 1989, 2000).

The chief purpose of this investigation is to study the incidence of the degree of abstraction when solving verbal arithmetic problems of change that require a single operation-addition or subtraction-in first, second, third, and fourth grade of Primary Education. Specifically, we wish to discover the following:

1. whether the degree of abstraction of the problem is important and whether it will have the same incidence on students of different grades.

2. whether the influence of the degree of abstraction will depend on the type of operation (addition or subtraction).
3. whether the degree of abstraction will be more or less efficient as a function of the location the unknown in the problems proposed.

4. whether the strategies used by participants to solve the problems will depend on the degree of abstraction of the proposed tasks.

\section{Method}

\section{Participants}

A total of 96 children were randomly selected to participate in this investigation. Of them, 24 were first graders of Primary Education, ages between 6 years and 7 years and 6 months $(M=6 ; 8) ; 24$ were second graders with an age range between 7 years and 8 years and 2 months $(M$ $=7 ; 7) ; 24$ were third graders, with ages ranging between 8 years and 9 years and 2 months $(M=8 ; 4)$, and lastly 24 were fourth graders with an age range between 9 years and 10 years and 4 months $(M=9 ; 8)$. The gender relation was very matched in all the samples (about $50 \%$ ). The parents' socio-economic level was low. The investigation was performed in Mexico, after having obtained the parents' and the educational center directors' permission.

\section{Material}

All the children were presented with 16 verbal problems of change, of which 8 were addition and 8 were subtraction. In turn, these 8 problems differed depending on the position of the unknown, which was either in the first term (4 problems) or in the result (4 problems). Likewise, taking into account the 4 above-mentioned levels of abstraction (objects, drawings, numbers and verbal), each of the 4 problems was presented at a different abstraction level. Thus, the following situations were presented:

1. Concrete addition problem with the unknown in the result.

2. Addition problem with drawings and the unknown in the result.

3. Numerical addition problem with the unknown in the result.

4. Verbal addition problem with the unknown in the result.

5. Concrete addition problem with the unknown in the first addend.

6. Addition problem with drawings and with the unknown in the first addend.

7. Numerical addition problem with the unknown in the first addend.

8. Verbal addition problem with the unknown in the first addend.

9. Concrete subtraction problem with the unknown in the result. 
10. Subtraction problem with drawings and the unknown in the result.

11. Numerical subtraction problem with the unknown in the result.

12. Verbal subtraction problem with the unknown in the result.

13. Concrete subtraction problem with the unknown in the minuend.

14. Subtraction problem with drawings and the unknown in the minuend.

15. Numerical subtraction problem with the unknown in the minuend.

16. Verbal subtraction problem with the unknown in the minuend.

\section{Procedure}

Tasks were presented in two sessions with 8 problems per session. The interviews were performed individually during the normal school schedule. In all the tasks, the experimenter read the problem slowly, repeating it as often as necessary. For example, the following problem: "Juan had some pencils. Lupita gave him 3 more pencils. Now Juan has 8 pencils. How many pencils did Juan have at the beginning?" At the same time as the experimenter read he indicated with his finger the quantity (of objects) corresponding to each one of the actors of the problem (Juan or Lupita). Thus, in concrete situations, real objects (marbles, candies, etc.) that represented the quantities and plastinated operational signs (+ or - and $=$ ) were presented, adopting the form of an algorithm with a horizontal format. For example, 4 candies were presented on a horizontal line, afterwards the plus sign (+) and then, 3 candies, the equal sign (=), and lastly, a blank space with a puppet in the upper part that received the name of the actor referred to by the unknown. In the case of the drawings, the situation was repeated, but this time, the series of objects and operational signs were drawn on various cardboards, including a blank cardboard with the puppet to represent the unknown, all of this placed on a horizontal line. In the case of numerical problems, a cardboard with the corresponding algorithm was presented, also horizontally, with the puppet in the blank space of the unknown. And lastly, for the verbal problems, there was only a cardboard with the corresponding verbal problem. The quantities used were not higher than 10 in any case.

The presentation order of the problems was counterbalanced. Each individual session was video-taped.

The children's responses were identified as correct or incorrect. Moreover, the strategy used by the participants was also recorded, as well as their responses to the question "How did you do it?" No feedback was provided nor was the correct response induced by the experimenter. Bermejo et al.'s (2002) proposal was used to classify the strategies employed: direct modeling, counting, and numerical facts.

\section{Analysis of Results and Discussion}

The results showed a reliability index (Cronbach's alpha) of .90 . We conducted a $4 \times 4 \times 2 \times 2$ (Grade [ $1^{\text {st }} v$ v. $2^{\text {nd }}$ vs. $3^{\text {rd }}$ vs. $4^{\text {th }}$ grade] $\times$ Type of problem [concrete vs. drawings vs. numerical vs. verbal] $\times$ Type of operation [addition vs. subtraction] $\times$ Location of unknown [in the first term vs. in the result]) ANOVA with repeated measures in the three last factors. The statistical package SPSS 11.0 was used for the analyses.

The ANOVA revealed significant effects for grade, $F(3$, $92)=33.12, p<.05$, type of problem, $F(3,276)=4.91, p$ $<.05$, and location of unknown, $F(1,92)=86.14, p<.05$. The variable type of operation was nonsignificant, $F(1,92)$ $=0.97, p=.32$. Therefore, grade, type of problem, and location of the unknown significantly affect the participants' achievement in solving the arithmetic problems presented.

The multiple comparisons performed with Tukey's test on the variable grade yielded significant differences between the fourth grade and the rest of the grades $(p<.05)$. The third graders were also significantly different from the second and first graders $(p<.05)$, but the differences between second graders and first graders were nonsignificant (see Table 1).In general, these data confirm those found in other investigations (Bermejo et al., 2002; Carpenter \& Moser, 1982; De Corte, Verschaffel, \& De Win, 1985; Riley et al., 1983) in the sense that achievement of students from higher grades is generally superior to that of children from lower grades.

Table 1

Mean Scores of the Levels of Abstraction when Solving Problems of Change

\begin{tabular}{|c|c|c|c|c|c|c|c|c|c|c|c|c|c|c|c|c|}
\hline \multirow[b]{3}{*}{ Grade } & \multicolumn{8}{|c|}{ Addition } & \multicolumn{8}{|c|}{ Subtraction } \\
\hline & \multicolumn{4}{|c|}{ Unknown in $1^{\text {st }}$ term } & \multicolumn{4}{|c|}{ Unknown in result } & \multicolumn{4}{|c|}{ Unknown in $1^{\text {st }}$ term } & \multicolumn{4}{|c|}{ Unknown in result } \\
\hline & $\mathrm{C}$ & $\mathrm{P}$ & $\mathrm{N}$ & V & $\mathrm{C}$ & $\mathrm{P}$ & $\mathrm{N}$ & V & $\mathrm{C}$ & $\mathrm{P}$ & $\mathrm{N}$ & $\mathrm{V}$ & $\mathrm{C}$ & $\mathrm{P}$ & $\mathrm{N}$ & V \\
\hline First & .20 & .25 & .16 & .12 & .54 & .45 & .50 & .66 & .33 & .25 & 20 & .20 & .41 & .33 & .33 & .54 \\
\hline Second & .12 & .20 & .29 & .29 & .91 & .75 & .37 & .87 & .50 & .37 & .33 & .29 & .37 & .29 & .37 & .75 \\
\hline Third & .37 & .45 & .45 & .54 & .70 & .70 & .91 & .83 & .50 & .50 & .54 & .75 & .66 & .66 & .79 & .87 \\
\hline Fourth & .87 & .91 & .87 & .87 & 1.0 & 1.0 & 1.0 & 1.0 & .87 & .83 & .83 & .91 & 1.0 & 1.0 & 1.0 & 1.0 \\
\hline
\end{tabular}

Note: $\mathrm{C}=$ Concrete level, $\mathrm{P}=$ Pictoric level, $\mathrm{N}=$ Numerical level, $\mathrm{V}=$ Verbal level. 
Likewise, the types of problems were compared in pairs, showing that, in general, the students performed significantly better in verbal problems than in numerical $(p<.01)$ or in pictorial ones $(p<.01)$. However, no significant differences were found among the other problems. These results are consistent with those found in other studies (Bermejo, 1990; De Corte et al., 1985; Riley et al., 1983), which found that children's achievement is higher in verbal problems than in algorithms. Figure 1 graphically shows the mean score in achievement of the different grades at the different levels of abstraction. As can be seen, there was, in general, a different developmental pattern for each grade, according to the levels of abstraction, so that the sequence from concrete to abstract affected the diverse grades unequally. Specifically, the fourth graders showed a clear "ceiling" effect in their achievement, indicating that the tasks were too easy for them. The third graders, however, showed a progressive change over the different levels of abstraction, with the problems using objects being the most difficult because the presence of such objects (which could also be drawings) may act as distracters at this developmental level instead of facilitating the comprehension of the problem. And lastly, the lower grades (first and second grade) presented better arithmetic achievement in the verbal problems and when using concrete materials, whereas their results in numerical problems were the worst.

Lastly, achievement was clearly better when the unknown was placed in the result than when it was in the first term. Other authors have reported the same finding (Bebout, 1990; Bermejo et al., 1998; Carpenter et al., 1983; De Corte \& Verschaffel, 1987), observing that children were more successful solving problems of change with the unknown in the result.

In Figure 2 can be seen the influence of the degree of abstraction on achievement in addition and subtraction problems as a function of the location of the unknown, in children from first to fourth grade of Primary Education. In general, a different developmental pattern can be observed as a function of the location of the unknown at each level of abstraction. If the

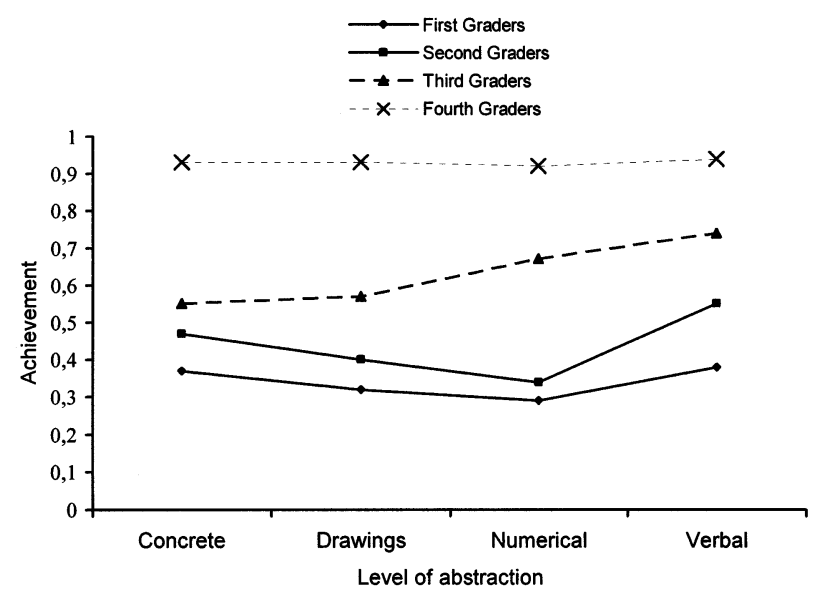

Figure 1. Mean scores of the four grades in the diverse levels of abstraction. unknown was located in the result, then there was a clear "ceiling" effect in fourth graders, whereas if it was placed in the first term, there was a "floor" effect in the 1st-grade students. The third graders showed progressive development as a function of the different levels of abstraction from the concrete to the verbal problems, regardless of the location of the unknown. Second grade was the most affected by the level of abstraction when the unknown was placed in the result. As can be seen, in this case, the presence of objects allowed the second graders to attain an achievement similar to that of the third graders, as was also observed with verbal problems. In the latter case, the similarity of the achievement was probably due to the fact that the second graders, like the third graders (and even the first graders), were accustomed to solving this kind of situations outside of the classroom. In contrast, the instruction in solving algorithms that the second graders had received was less consolidated than in the third graders.

The ANOVA revealed significant double interactions of Type of problem $\times$ Location of unknown, $F(3,276)=3.41$, $p<.05$; and of Type of operation $\times$ Location of unknown, $F(1,92)=18.34, p<.05$; and significant triple interactions of Grade $\times$ Type of problem $\times$ Location of unknown, $F(9$, $276)=3.15, p<.05$; Grade $\times$ Type of operation $\times$ Location of unknown, $F(3,92)=4.30, p<.05$; and Type of problem $\times$ Type of operation $\times$ Location of unknown, $F(3,276)=$ $2.82, p<.05$. Lastly, the interaction Grade $\times$ Type of problem $\times$ Type of operation $\times$ Location of unknown was also significant, $F(9,276)=3.19, p<.05$.

If, to save space, we only focus on the interaction Grade $\times$ Type of problem $\times$ Location of unknown, the analysis of the simple effects of the type of problem at the levels of the other factors showed the following results when the unknown was placed in the result: in the first grade, verbal addition problems were significantly different from problems with drawings, $F(3,90)=1.91, p<.05$, in the sense that the children were more successful with the former. Likewise, verbal subtraction problems were significantly different from

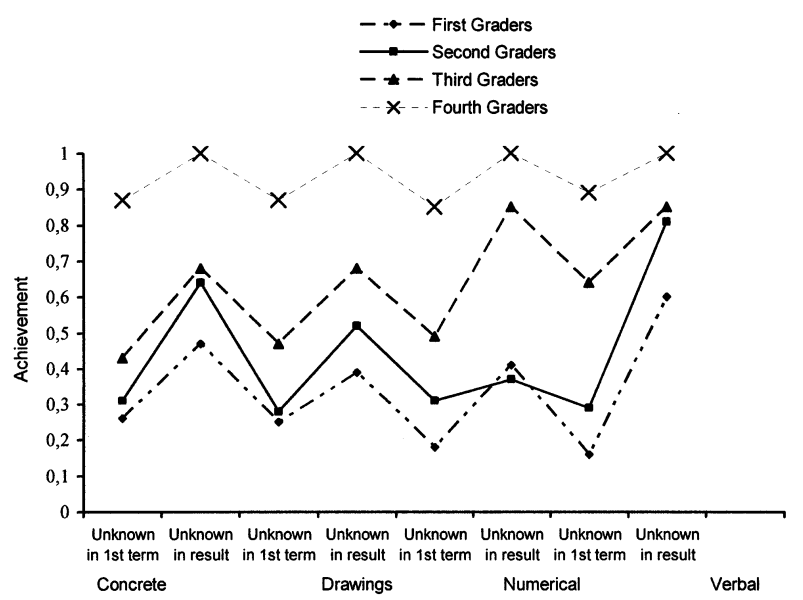

Figure 2. Mean scores of the four grades according to the level of abstraction and the location of the unknown. 
numerical subtraction problems, $F(3,90)=2.16, p<.05$, with higher achievement in the former. In the second grade, when the unknown was located in the result, concrete addition problems were significantly different from problems with drawings and numerical problems, $F(3,90)=15.76, p<.01$, with higher achievement in concrete tasks. Likewise, verbal addition problems and addition problems with drawings were significantly different from numerical problems, $F(3,90)=$ 15.76, $p<.01$, with the latter being more difficult than the former (verbal addition problems and addition problems with drawings). These data are in accordance with those obtained in other investigations of the increase in achievement when using the construction of drawings and the pictorial representation of the problems in comparison to numerical problems (Cummins, 1991; Moyer et al., 1984; VlahovicStetic, 1999; Wolters, 1983; Zhou \& Zhang, 2000). Lastly, in second grade, there were significant differences between the verbal subtraction problems with the unknown in the first term and all the other subtraction problems with the unknown in the result, $F(3,90)=6.32, p<.01$. In the remaining grades, there were no significant differences.

With regard to the strategies used by students to solve the problems as a function of the degree of abstraction, we shall briefly analyze some aspects of the most notable strategies: direct modeling, counting, and numerical facts (see Bermejo et al., 2002). Direct modeling is used significantly more often in concrete problems and with drawings than in verbal and numerical problems, $F(3,276)=5.06, p<.05$, as reported by other authors (Bermejo et al., 1998; Carpenter, Hiebert, \& Moser, 1983; Fuson \& Briars, 1990; Fuson \& Burghardt, 2003). Counting strategies appear mainly at the concrete, pictorial, and verbal levels in second grade, whereas the numerical level is especially noted in fourth grade. More specifically, in second grade, counting in was significantly higher drawing and verbal problems than in numerical problems, $F(3,90)=3.71, p<.05$, and, in third grade, it was significantly higher in concrete problems than in verbal ones, $F(3,90)=2.76, p<.05$. It is interesting to note that counting strategies in general are much more frequent when the unknown is located in the result than when it is located in the first term, as can be seen in Figure 3. The significance of the interaction Type of problem $\times$ Location of unknown, $F(3,276)=4.85, p<.05$, indicates that counting is used in a different way depending on the type of problem and the location of the unknown. In effect, verbal problems lead to a higher number of counting strategies when the unknown is in the result, and its frequency is also the lowest in these problems when the unknown is located in the first term, $F(3,276)=3.64, p<.05$.

Concerning the strategy of numerical facts, we note the significance of the variables grade, $F(3,92)=41.40, p<.01$, and problem, $F(3,276)=13.05, p<.05$. Multiple Tukey comparisons of grade showed that there were significant differences in the use of this strategy between fourth graders and first and second graders $(p<.05)$. Likewise, there were significant differences between third graders and first and

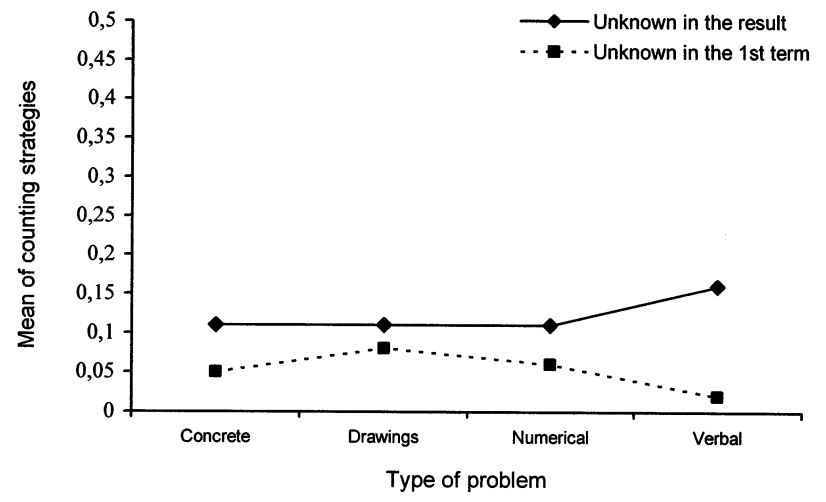

Figure 3. Interaction of the type of problem and the location of the unknown in the counting strategies.

second graders $(p<.05)$, and, lastly, between second graders and first graders $(p<.05)$ (see Bermejo et al., 1998; Carpenter $\&$ Moser, 1982, 1984). Using the same Tukey test in the type of problem, we found that the numerical facts were used significantly more in verbal problems than in concrete and pictorial problems $(p<.01)$, and also more in numerical problems than in concrete and pictorial problems $(p<.01)$.

\section{Conclusions}

As expected, the participants display a development according to their schooling, so that, in general, students' mathematical achievement progressively increases as they advance through the school grades.

Likewise, achievement improved slightly more in adding tasks than in subtraction tasks, although without reaching statistically significant differences between the operations. This improvement probably is due, to a great extent, to the different importance assigned to these operations in school instruction, as there are usually no differences between these operations in children's achievement. There were significant differences in student's mathematical achievement as a function of the location of the unknown, with the problem being easier when the unknown was located in the result.

The degree of abstraction is especially interesting in the three lower grades (first, second, and third), although for different reasons. The $3^{\text {rd }}$-grade students showed progressive mathematical achievement as a function of the levels of abstraction (concrete $\ddagger$ pictorial $\ddagger$ numerical $\ddagger$ verbal) because, at this developmental level, objects and drawings are more of a distracter than an aid to solve the proposed problems, whereas solving numerical tasks is easy for them because in this grade, they receive more instruction in class about the algorithms of adding and subtracting. In contrast, $1^{\text {st }}$ - and $2^{\text {nd }}$-grade students present an involutional pattern according to these levels of abstraction, except for verbal problems, where their achievement is the highest, along with the $3^{\text {rd }}$-grade students. These results are probably due to the children's informal 
knowledge and extra-academic familiarity with situations in their daily lives that remind them of the verbal problems. With regard to the above-mentioned involutional pattern, it seems clear that the $1^{\text {st }}$ - and $2^{\text {nd }}$-grade students of Primary Education learn mathematics better with the help of objects or drawings than just using the algorithm of these operations.

With regard to the strategies used by the participants, the students resort especially to modeling strategies in the lower grades. Moreover, the frequency of use of a specific strategy also depends on the type of operation and the location of the unknown.

Lastly, this investigation found, in general, consistency in the degree of difficulty of problems of change, a developmental tendency in students' achievement, a sequence of abstraction from the concrete to the abstract in the first two grades, and finally, the use of specific and varied strategies.

\section{References}

Bebout, H. (1990). Children's symbolic representation of addition and subtraction word problems. Journal for Research in Mathematics Education, 21, 123-131.

Bergeron, J., \& Hersovics, N. (1990). Psychological aspects of learning early arithmetic. In P. Nesher \& J. Kilpatrick (Eds.), Mathematical and cognition (pp. 31-52). Cambridge, NY: Cambridge University Press.

Bermejo, V. (1990). El niño y la aritmética. Madrid: Paidós.

Bermejo, V. (Ed). (2004). Cómo enseñar matemáticas para aprender mejor. Madrid: CCS.

Bermejo, V., Lago, M.O., \& Rodríguez, P. (1998). Aprendizaje de la adición y sustracción. Secuenciación de los problemas verbales según su dificultad. Revista de Psicología General y Aplicada, 51, 533-552.

Bermejo, V., Lago, M.O., Rodríguez, P., Dopico, C., \& Lozano, J.M. (2002). PEI. Un programa de intervención para la mejora del rendimiento matemático. Madrid: Editorial Complutense.

Bruner, J.S. (1966). Toward a theory of instruction. Cambridge, MA: Harvard University Press.

Cai, J. (2000). Mathematical thinking involved in U.S. and Chinese students' solving of process-constrained and process-open problems. Mathematical Thinking and Learning, 2, 309-340.

Canobi, K., Reeve, R., \& Pattison, Ph. (2003). Patterns of knowledge in children's addition. Developmental Psychology, 39, 521-534.

Carpenter, T.P. (1986). Conceptual knowledge as a foundation for procedural knowledge: Implications from research on the initial learning of arithmetic. In J. Hiebert (Ed.), Conceptual and procedural knowledge: The case of mathematics (pp. 113-132). Hillsdale, NJ: Erlbaum.

Carpenter, T.P., Ansell, E., Franke, M., Fennema, E., \& Weisbeck, L. (1993). Models of problem solving: A study of kindergarten children's problem-solving processes. Journal for Research in Mathematics Education, 24, 427-440.

Carpenter, T.P., Hiebert, J., \& Moser, J.M. (1981). Problem structure and first-grade children's initial solution processes for simple addition and subtraction problems. Journal for Research in Mathematics Education, 12, 27-29.

Carpenter, T.P., Hiebert, J., \& Moser, J.M. (1983). The effect of instruction on children's solutions of addition and subtraction word problems. Educational Studies in Mathematics, 14, 55-72.

Carpenter, T.P., \& Moser, J.M. (1982). The development of addition and subtraction problem-solving skills. In T.P. Carpenter, J.M. Moser, \& T.A. Romberg (Eds.), Addition and subtraction: A cognitive perspective (pp. 9-24). Hillsdale, NJ: Erlbaum.

Carpenter, T.P., \& Moser, J.M. (1983). The acquisition of addition and subtraction concepts. In R. Lesh \& M. Landau (Eds.), Acquisition of mathematics: Concepts and processes (pp. 744). NY: Academic Press.

Carpenter, T.P., \& Moser, J.M. (1984). The acquisition of addition and subtraction concepts in grades one through three. Journal for Research in Mathematics Education, 15, 179- 202.

Chen, M.H. (1999). Children's solution of arithmetic word problems as a function of number size. Dissertation Abstracts International: Section B: The Sciences and Engineering, 59 (10-B): 5597.

Christou, C., \& Philippou, G. (1998). The developmental nature of ability to solve one-step word problems. Journal for Research in Mathematics Education, 29, 436-442.

Cohen, S.A., \& Stover, G. (1981). Effects of teaching sixth grade students to modify format variables of math word problems. Reading Research Quarterly, 16, 175-200.

Cummins, D. (1991). Children's interpretations of arithmetic word problems. Cognition and Instruction, 8, 261-289.

De Corte, E., \& Verschaffel, L. (1985). Beginning first graders' initial representation of arithmetic word problems. The Journal of Mathematical Behavior, 4, 3-21.

De Corte, E., \& Verschaffel, L. (1987). The effect of semantic structure on first graders' strategies for solving addition and subtraction word problems. Journal for Research in Mathematics Education, 18, 363-381.

De Corte, E., Verschaffel, L., \& De Win, L. (1985). Influence of rewording verbal problems on children's problem representations and solutions. Journal of Educational Psychology, 77, 460-470.

Fuson, K.C., \& Briars, D.J. (1990). Using a base-ten blocks learning/teaching approach for first and second grade placevalue and multidigit addition and subtraction. Journal for Research in Mathematics Education, 21, 108-206.

Fuson, K.C., \& Burghardt, B.H. (2003). Multidigit addition and subtraction methods invented in small groups and teacher support of problem solving and reflection. In A.J. Baroody \& A. Dowker (Eds.), The development of arithmetic concepts and skills: Constructing adaptive expertise. Studies in mathematical thinking and learning. (pp. 267-304). Mahwah, NJ: Erlbaum.

Fuson, K.C., Smith, S., \& LoCicero, A. (1997). Supporting Latino first graders' ten-structured thinking in urban classrooms. Journal for Research in Mathematics Education, 28, 738-766.

Fuson, K.C., \& Willis, G.B. (1989). Second graders' use of schematic drawings in solving addition and subtraction word problems. Journal of Educational Psychology, 81, 514- 520. 
Ginbayashi, K. (1984). Principles of mathematics educationAchievements of AMI. Tokyo: Association of Mathematical Instruction.

Grouws, D. A. (Ed.). (1992). Handbook of research on mathematics teaching and learning. New York: Macmillan.

Hatano, G. (1980, April). Mental regrouping strategy for addition: An alternative model to counting-on. Paper presented at the National Council of Teachers of Mathematics Research Presession, Seattle, WA.

Hatano, G. (1982). Learning to add and subtract: A Japanese perspective. In T.P. Carpenter, J.M. Moser, \& T.A. Romberg (Eds.), Addition and subtraction: A cognitive perspective (pp. 211-223). Hillsdale, NJ: Erlbaum.

Hiebert, J. (1982). The position of unknown set in children's solution of verbal arithmetic problems. Journal for Research in Mathematics Education, 13, 341-349.

Hughes, M. (1986). Children and number: Difficulties in learning mathematics. Oxford, UK: Blackwell.

Kamii, C., Kirkland, L., \& Lewis, B.A. (2001). Representation and abstraction in young children's numerical reasoning. In National Council of Teachers of Mathematics (Ed.), The roles of representation in school mathematics (pp. 24-34). Yearbook 2001. Reston, VA: Author.

Kamii, C., Lewis, B.A., \& Kirkland, L.D. (2001a). Manipulatives: When are they useful? Journal of Mathematical Behavior, 20, 21-31.

Kamii, C., Lewis, B.A., \& Kirkland, L.D. (2001b). Fluency in subtraction compared with addition. Journal of Mathematical Behavior, 20, 33-42.

Kato, Y., Kamii, C., Ozaki, K., \& Nagahiro, M. (2002). Young children's representations of groups of objects: The relationship between abstraction and representation. Journal for Research in Mathematics Education, 33, 30-45.

Kennedy, L.M., \& Tipps, S. (1994). Guiding children's learning of mathematics. Belmont, CA: Wadsworth.

Labinowicz, E. (1985). Learning from students: New beginnings for teaching numerical thinking. Menlo Park, CA: AddisonWesley.

Larkin, J.H., \& Simon, H.A. (1987). Why a diagram is (sometimes) worth ten thousand words. Cognitive Science, 19, 65-100.

Lindvall, C.M., Tamburino, J.L., \& Robinson, L. (1982, March). An exploratory investigation of the effect of teaching primary grade children to use specific problem solving strategies in solving simple arithmetic story problems. Paper presented at the annual meeting of the American Educational Research Association, New York.

Maccini, P., \& Hughes, Ch. (2000). Effects of a problem-solving strategy on the introductory algebra performance of secondary students with learning disabilities. Learning Disabilities Research and Practice, 15, 10-21.

Moyer, J.C., Sowder, L., Threadgill-Sowder, J., \& Moyer, M.B. (1984). Story problem formats: Drawn versus verbal versus telegraphic Journal for Research in Mathematics Education, 15, 342-351.

National Council of Teachers of Mathematics. (2000). Principles and standards for school mathematics. Reston, VA: Author.
National Council of Teachers of Mathematics. (1989). Curriculum and evaluation standards for school mathematics. Reston, VA: Author.

Organisation for Economic Co-operation and Development/PISA (2005). Informe Pisa 2003. Aprender para el mundo del mañana. Madrid: Author/Santillana.

Piaget, J. (1951). Play, dreams, and imitation in childhood. New York: Norton.

Piaget, J. (1970). Science of education and the psychology of the child. New York: Orion Press.

Quintero, A.H. (1983). Conceptual understanding in solving twostep word problems with a ratio. Journal for Research in Mathematics Education, 14, 102-112.

Resnick, L., \& Omanson, S. F. (1987). Learning to understand arithmetic. In R. Glaser (Ed.), Advances in instructional psychology (pp. 41-95). Hillsdale, NJ: Erlbaum.

Riley, M.S., \& Greeno, J.G. (1988). Developmental analysis of understanding language about quantities and of solving problems. Cognition and Instruction, 5, 49-101.

Riley, M.S., Greeno, J.G., \& Heller, J.I. (1983). Development of children's problem solving ability in arithmetic. In H.P. Ginsburg (Ed.), The development of mathematical thinking (pp. 153-196). New York: Academic Press.

Selva, A.C., \& Brandao, A.C. (2000). A notaçao escrita na resoluçao de problemas por crianças pre-escolares. Psicología: Teoria y Pesquisa, 16, 241-249.

Vergnaud, G. (1982). A classification of cognitive tasks and operations of thought involved in addition and subtraction problems. In T.P. Carpenter, J.M. Moser, \& T.A. Romberg (Eds.), Addition and subtraction: A cognitive perspective (pp. 39-59). Hillsdale, NJ: Erlbaum.

Vlahovic-Stetic, V. (1999). Word-problem solving as a function of problem type, situational context and drawing. Studia Psychologica, 41, 49-62.

Wearne, D., \& Hiebert, J. (1988). A cognitive approach to meaningful mathematics instruction: Testing a local theory using decimal numbers. Journal for Research in Mathematics Education, 19, 371-384.

Willis, G.B., \& Fuson, K.C. (1988). Teaching children to use schematic drawings to solve addition and subtraction word problems. Journal of Educational Psychology, 80, 192- 201.

Wolters, M.A.D. (1983). The part-whole schema and arithmetical problems. Educational Studies in Mathematics, 14, 127-138.

Yancey, A.V. (1981). Pupil-generated diagrams as a strategy for solving word problems in elementary mathematics. University of Louisville. (ERIC Document Reproduction Service No. ED 260922).

Zhou, X., \& Zhang, M. (2000). Effects of analyzing quantity sets and generating diagrams in relational word problem solving. Psychological Science China, 23, 611-618.

Zhou, X., \& Zhang, M. (2003). Influence of situation complexity on solving addition and subtraction word problems. Acta Psychologica Sinica, 35, 195-200.

Received September, 25, 2006 Revision received February, 6, 2007 Accepted May, 24, 2007 